\title{
EXPERIMENTAL CUTANEOUS LEISHMANIASIS: LANGERHANS CELLS INTERNALIZE LEISHMANIA MAJOR AND INDUCE AN ANTIGEN-SPECIFIC T-CELL RESPONSE
}

\author{
Heidrun Moll \\ Institute of Clinical Microbiology \\ University of Erlangen-Nümberg \\ Wasserturmstrasse 3 \\ W-8520 Erlangen, Germany
}

\section{INTRODUCTION}

Human leishmaniasis constitutes a diverse group of diseases caused by protozoa of the genus Leishmania. The parasites are transmitted by sandflies and the infection is initiated by introduction of promastigotes into the skin at the site of the vector's bite. In the mammalian host, Leishmania parasites exist as obligatory intracellular amastigotes residing in mononuclear phagocytes. The diseases vary in severity from the self-healing cutaneous leishmaniasis, characterized by a localized cutaneous lesion at the site of primary infection, to the progressive visceral leishmaniasis, where the parasites disseminate from the original skin lesion to local lymph nodes and then to spleen, liver and bone marrow. The clinical manifestation depends primarily on the species of parasite, but also on the genetic make-up of the host. The T cell-mediated immunity is crucial for the outcome of infection because activated $\mathrm{T}$ cells release various lymphokines that promote either the spreading or the elimination of parasites 1,2 .

The entry of Leishmania into host cells occurs via attachment to cell surface receptors and subsequent internalization by phagocytosis. Receptor-ligand binding involves the receptor for complement component $\mathrm{C} 3 \mathrm{bi}, \mathrm{CR} 3$, and the mannose-fucose receptor on macrophages ${ }^{3}$. Infected macrophages express parasite antigen on their surface and thus serve as antigen-presenting cells for induction of a specific T-cell response.

In the mammalian skin, there are two appropriate cell types that would be in contact with inoculated Leishmania parasites - dermal macrophages and epidermal Langerhans cells (LC). LC express CR3 (Refs. 4, 5) and they are potent antigen-presenting cells bearing high levels of major histocompatibility complex (MHC) class II antigens. In contrast to macrophages, however, which are known to play a central role in the course of infection 6 , the function of LC in leishmaniasis has so far not obtained adequate attention.

We used Leishmania major, the cause of human cutaneous leishmaniasis in the Old World, for analysis of the following issues in the mouse model: (1) the interaction of LC 
with $L$. major, (2) the efficacy of LC to present $L$. major antigen to T cells, and (3) the ability of LC to transport $L$. major antigen from the skin into lymphoid tissues for stimulation of $\mathrm{T}$ cells.

\section{LANGERHANS CELLS CAN BE INFECTED BY L. MAJOR}

In order to investigate the interaction of $L C$ with $L$. major in vitro, single-cell suspensions of epidermal cells were prepared from ear skin of $\mathrm{BALB} / \mathrm{c}$ mice by trypsinization procedures as previously described ${ }^{7}$. Freshly isolated epidermal cells were incubated with L. major amastigotes for $24 \mathrm{~h}$. Subsequently, the cultures were harvested for removal of extracellular parasites and identification of infected epidermal cells by cytochemistry.

Double labeling combining immunoenzymatic labeling ( $A B C$ method $^{8}$ ) to detect L. major antigens and immunofluorescence staining for expression of MHC class II (Ia) molecules revealed that only $\mathrm{Ia}^{+}$epidermal cells but not $\mathrm{Ia}^{-}$cells contained $L$. major antigen. Because $\mathrm{LC}$ are the only $\mathrm{Ia}^{+}$cells in the normal epidermis, this finding demonstrated that epidermal LC can be parasitized by $L$. major. Furthermore, ultrastructural studies showed that $\mathrm{LC}$ accomodated intact amastigotes which were secluded within phagosomes (Figure 1 ). The ingestion of $L$. major by LC was blocked by anti-CR 3 antibodies but could not be reduced by a soluble inhibitor of the mannose-fucose receptor. This indicated that in contrast to the uptake of Leishmania by macrophages, which requires the combined action of CR3 and the mannose-fucose receptor ${ }^{3}$, the internalization by LC is mediated primarily by CR3.

Only freshly isolated LC were able to ingest $L$. major. When parasites were added to cultured epidermal cells, the rate of infection was inversely correlated with the time of preincubation. No uptake could be detected after overnight culture of epidermal cells prior to addition of parasites (Table 1 ).

L. major-containing LC could not only be identified after culture in vitro but were also detectable in situ in the lesions of mice that had been intradermally infected with L. major promastigotes. This was demonstrated in skin sections by mixed labeling 8 of LC with an antibody to nonlymphoid dendritic cells (NLDC-145, Ref. 10) and an antiserum to $L$. major. NLDC- $145^{+}$LC expressing $L$. major antigen could only be traced in the dermal infiltrate, but not in the epidermis, and constituted less than $1 \%$ of nonlymphoid mononuclear cells in this area.

Table 1. The ability of LC to ingest $L$. major decreases with the time of culture. ${ }^{1}$

\begin{tabular}{cc}
$\begin{array}{c}\text { Time of culture before } \\
\text { addition of } L . \text { major (hours) }\end{array}$ & $\begin{array}{c}\text { infected } L C \\
(\% \text { of control } ; \overrightarrow{\mathbf{x}} \pm \text { SD) }\end{array}$ \\
\hline 0 (control) & 100 \\
2 & $59 \pm 12$ \\
5 & $32 \pm 11$ \\
9 & $8 \pm 5$ \\
16 & $0 \pm 0$ \\
24 & $3 \pm 1$
\end{tabular}

${ }^{1}$ L.major amastigotes were added to epidermal cell cultures at various time points. After additional $24 \mathrm{~h}$, the cultures were harvested, extracellular parasites were removed, and the rate of infection of $\mathrm{LC}$ was determined by fluorescence microscopic analysis after staining with acridine orange and ethidium bromide ${ }^{9}$. 


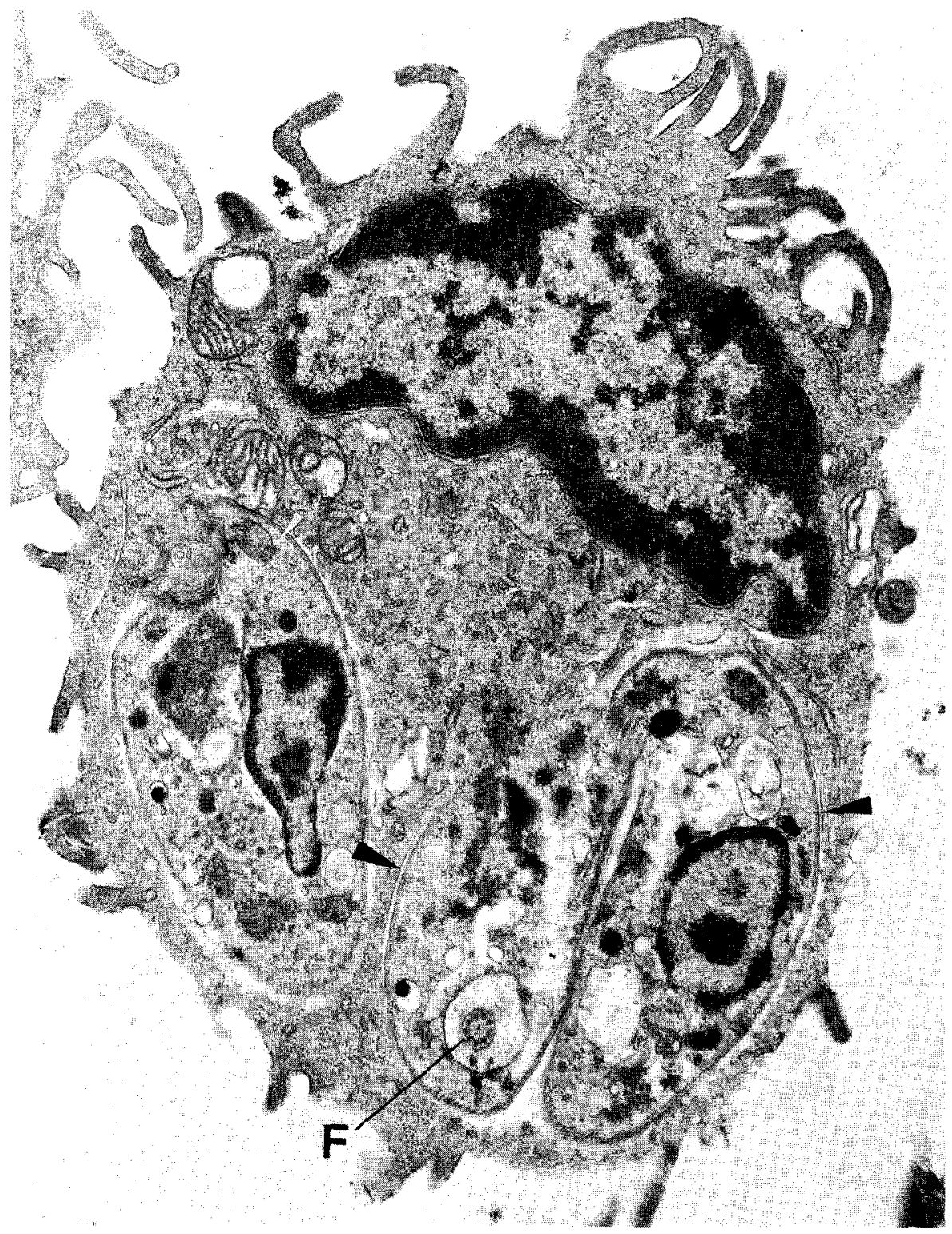

Figure 1. Electron microscopic documentation of a $L$. major-infected $L C$ containing two amastigotes within one phagosome and a single organism within another phagosome. Note the unit mebrane of the phagosome (arrowheads) and the flagellum (F). Magnification $=x 15,000$. (Courtesy of Klemens Rappersberger, M. D.)

The maximum level of infection in culture was $25 \%$ of total LC and the majority of infected LC had only ingested one parasite (mean: 1.4 amastigotes). Most interestingly, time course analysis revealed that the average number of organisms per infected cell did not increase after $24 \mathrm{~h}$ of culture, and by one week, L. major-containing LC were no longer detectable. Thus, LC are able to restrain parasite replication. This is in contrast to macrophages which are permissive to parasite infection unless they are activated by cytokines such as as interferon- $\boldsymbol{\gamma}^{11}$. 
The above findings showed that the parasite load of $\mathrm{LC}$ in vitro and in vivo is much lower than that of macrophages. This suggests that endocytosis of $L$. major by LC is not primarily aimed at antigen scavenging, the characteristic of macrophages. In addition, LC did not support intracellular parasite multiplication and are therefore unlikely to account for the massive expansion of amastigotes usually observed in the infected skin. It is conceivable, however, that the major function of $\mathrm{LC}$, which are known to be amongst the most active antigen-presenting cells ${ }^{12}$, is the presentation of $L$. major antigen to T cells. To test this possibility, we investigated the ability of LC to stimulate L. major-primed $\mathrm{T}$ cells in vitro.

\section{LANGERHANS CELLS ARE POTENT STIMULATORS OF AN ANTIGEN-SPECIFIC T-CELL RESPONSE TO L. MAJOR}

To assess the efficiency of epidermal antigen-presenting cells, we used unselected epidermal cell populations which contain $2 \%$ to $4 \%$ LC. The results demonstrated that epidermal cells are able to present $L$. major antigen in vitro to $T$ cells from primed mice ${ }^{13}$. The heterogeneous epidermal cells were remarkably efficient because the doses required for optimal responses were equivalent to merely 250 to $2000 \mathrm{LC}$ per culture. The T cellstimulatory effect of epidermal cells could indeed be attributed to LC because removal of those cells completely abrogated the response. LC stimulated both T-cell proliferation and lymphokine production; the reaction was antigen-specific and could be induced by antigen in L. major lysate as well as by antigen derived from viable parasites ${ }^{13}$. The finding that only freshly isolated LC, but not cultured LC, were able to present L. major antigen was in line with our observation that only fresh LC could internalize parasites. This is reminiscent of earlier reports showing that freshly explanted LC can process native antigen for presentation to primed T cells, whereas cultured LC have lost this ability but are highly active mediators of stimuli that do not require antigen processing ${ }^{14-16}$. Freshly isolated LC would reflect the properties of intracutaneous LC, and LC cultured for several days would be the in vitro equivalents of lymphoid dendritic cells derived from LC that have migrated to lymph nodes.

\section{MAJOR-BEARING LANGERHANS CELLS MIGRATE FROM THE INFECTED SKIN TO THE DRAINING LYMPH NODE}

Evidence is accumulating that LC are capable of transporting antigens from peripheral non-lymphoid tissues via the lymphatics into lymphoid tissues for presentation to $T$ cells ${ }^{17,18}$. Therefore, it was of interest to investigate whether dendritic cells carrying parasite antigen can be localized in lymph nodes draining the site of cutaneous infection with $L$. major. For this purpose, frozen sections of skin and lymph nodes from infected mice were analyzed by immunocytochemistry. In infected skin, the number of LC residing in the epidermis decreased rapidly within a few days after infection, whereas a gradually increasing number of LC appeared in the dermal compartment. Using mixed-labeling techniques ${ }^{8}$, dendritic cells displaying $L$. major antigen were found not only in the dermis but also in the regional lymph node. In the early phase of infection, expression of parasite antigen in the lymph nodes was confined to dendritic cells and could not be detected on macrophages. Those lymph node cells had the potency of presenting parasite antigen to $T$ cells because they stimulated antigen-specific $T$-cell proliferation in vitro and, after transfer to naive recipients, they induced DTH reactivity to $L$. major antigen. These findings indicate that LC capture $L$. major antigen in the skin and transport it to the regional lymph node for initiation of the $\mathrm{T}$-cell immune response. 


\section{CONCLUDING REMARKS}

In summary, our results suggest an important role of LC during cutaneous leishmaniasis. They support the concept that, upon inoculation of $L$. major into the skin, viable parasites are ingested not only by macrophages but also by LC that have migrated into the dermis. After appropriate processing of the organisms, LC would interact with antigenspecific $T$ cells in two different ways. On the one hand, they are capable of carrying parasite antigen from the skin to the draining lymph node and presenting it to quiescent $T$ cells of the circulating pool. On the other hand, LC may present parasite antigen to effector $T$ cells infiltrating the cutaneous lesion and regulate the local immune response.

Several implications arise from these findings which are important for our understanding of the pathogenesis of cutaneous leishmaniasis. The first aspect relates to the well-documented phenomenon that resistance and susceptibility to infection can be attributed to $\mathrm{CD}^{+}{ }^{+} \mathrm{T}$-cell populations with different patterns of lymphokine activity ${ }^{1,2}$. Release of interferon- $\gamma$ appears to promote protection, whereas interleukin 4 has been suggested to facilitate survival of parasites. The possibility exists that different types of antigen-presenting cells (i.e. LC, lymphoid dendritic cells, macrophages and B cells) favor the expansion of disparate $T$-cell subsets on the basis of providing different costimulatory signals. The second point relates to the role of different parasite antigens. The processing machinery of LC may differ from that of other antigen-presenting cells and favor the presentation of distinct antigens or particular epitopes of a given antigen. A more detailed knowledge of this issue will be important for choosing the route of administration of potentially protective antigens. Finally, it will be of interest to analyze the mechanisms underlying the disparate permissiveness of resident macrophages and LC to infection with L. major or other Leishmania species. This may help to understand the varying disease patterns caused by different species of parasites. Current work in our laboratory addresses these issues. The above considerations emphasize that experimental cutaneous leishmaniasis provides an excellent model to study the role of $\mathrm{LC}$ in vivo during infectious diseases.

\section{ACKNOWLEDGMENTS}

It has been my privilege to study the role of $\mathrm{LC}$ in leishmaniasis in collaboration with the gifted students Christine Blank, Harald Fuchs and Antje Will. I am also very grateful to Dr. Klemens Rappersberger, University of Vienna Medical School, who performed the electron microscopical analyses. This work was supported by the Deutsche Forschungsgemeinschaft (SFB 263/A2).

\section{REFERENCES}

1. H. Moll and M. Röllinghoff, Resistance to murine cutaneous leishmaniasis is mediated by $\mathrm{T}_{\mathrm{H}^{1}} \mathbf{\text { cells}}$, but disease-promoting $\mathrm{CD}^{+}$cells are different from $\mathrm{T}_{\mathbf{H}^{2}}$ cells, Eur. J. Immunol. 20:2067 (1990).

2. R. M. Locksley and P. Scott, Helper T-cell subsets in mouse leishmaniasis: induction, expansion and effector function, in: "Immunoparasitology Today", C. Ash and R. B. Gallagher, eds., Elsevier Science Publishers Ltd., Cambridge, UK (1991).

3. J. M. Blackwell, A. B. Ezekowitz, M. B. Roberts, J. Y. Channon, R. B. Sim, and S. Gordon, Macrophage complement and lectin-like receptors bind Leishmania in the absence of serum, J. Exp. Med. 162: 324 (1985).

4. G. Stingl, E. C. Wolff-Schreiner, W. J. Pichler, F. Gschnait, W. Knapp, and K. Wolff, Epidermal Langerhans cells bear Fc and C3 receptors, Nature (London) 268:245 (1977).

5. N. Romani, G. Stingl, E. Tschachler, M. D. Witmer, R. M. Steinman, E. M. Shevach, and G. Schuler, 
The Thy-1 bearing cell of murine epidermis: a leukocyte distinct from Langerhans cell and perhaps related to NK cells, J. Exp. Med. 161:1368 (1985).

6. W. Solbach, H. Moll, and M. Rollinghoff, Lymphocytes play the music, but the macrophage calls the tune, Immunol. Today 12:4 (1991).

7. G. Schuler and F. Koch, Enrichment of epidermal Langerhans cells, in: "Epidermal Langerhans Cells", G. Schuler, ed., CRC press, Boca Raton (1991).

8. R. Gillitzer, R. Berger, and H. Moll, A reliable method for simultaneous demonstration of two antigens using a novel combination of immunogold-silver staining and immunoenzymatic labeling, $J$. Histochem. Cytochem. 38:307 (1990).

9. J. Y. Channon, M. B. Roberts, and J. M. Blackwell, A study of the differential respiratory burst activity elicited by promastigotes and amastigotes of Leishmania donovani in murine resident peritoneal macrophages, Immunol. 53:345 (1984).

10. G. Kraal, M. Breel, M. Janse, and G. Bruin, Langerhans cells, veiled cells and interdigitating cells in the mouse recognized by a monoclonal antibody, J. Exp. Med. 163:981 (1986).

11. C. F. Nathan, H. W. Murray, M. E. Wiebe, and B. Y. Rubin, Identification of interferon- $\gamma$ as the lymphokine that activates human macrophage oxidative metabolism and antimicrobial activity, $J$. Exp. Med. 158:670 (1983).

12. G. Stingl and E. M. Shevach, Langerhans cells as antigen-presenting cells, in: "Epidermal Langerhans Cells", G. Schuler, ed., CRC press, Boca Raton (1991).

13. A. Will, C. Blank, M. Röllinghoff, and H. Moll, Murine epidermal Langerhans cells are potent stimulators of an antigen-specific $T$ cell response to Leishmania major, the cause of cutaneous leishmaniasis, Eur. J. Immunol. 22:1341 (1992).

14. G. Schuler and R. M. Steinman, Murine epidermal Langerhans cells mature into potent immunostimulatory dendritic cells in vitro, J. Exp. Med. 161:526 (1985).

15. N. Romani, S. Koide, M. Crowley, M. Witmer-Pack, A. M. Livingstone, G. C. Fathman, K. Inaba, and R. M. Steinman, Presentation of exogenous antigens by dendritic cells to $T$ cell clones. Intact protein is presented best by immature, epidermal Langerhans cells, J. Exp. Med. 169:1169 (1989).

16. J. W. Streilein and S. Grammer, In vitro evidence that Langerhans cells can adopt two functionally distinct forms capable of antigen presentation to T lymphocytes, J. Immunol. 143:3925 (1989).

17. S. E. Macatonia, S. C. Knight, A. J. Edwards, S. Griffiths, and P. Fryer, Localization of antigen on lymph node dendritic cells after exposure to the contact sensitizer fluorescein isothiocyanate. $J$. Exp. Med. 166:1654 (1987).

18. C. P. Larsen, R. M. Steinman, M. Witmer-Pack, D. F. Hankins, P. J. Morris, and J. M. Austyn, Migration and maturation of Langerhans cells in skin transplants and explants, J. Exp. Med. 172:1483 (1990). 